\title{
Prospective multicentre study of risk factors associated with delayed healing of recurrent duodenal ulcers (RUDER)
}

Division of

Gastroenterology,

CHUV/PMU, Lausanne,

Switzerland

D Armstrong

A L Blum

Department of Internal Medicine, University of Marburg, Germany

R Arnold

Department of

Gastroenterology,

Technical University,

Munich, Germany

$M$ Classen

Institut für Numerische

Statistik, Cologne,

Germany

M Fischer

Division of

Gastroenterology,

University of Essen,

Germany

H Goebell

Correspondence to:

Dr Armstrong, Intestinal

Disease Research Unit,

McMaster University, Room

HSC-3N5C, 1200 Main Stree

West, Hamilton, Ontario

L8N 3Z5, Canada.

Accepted for publication

9 February 1993

D Armstrong, R Arnold, M Classen, $M$ Fischer, H Goebell, A L Blum, the RUDER Study Group

\begin{abstract}
Risk factors for delayed duodenal ulcer healing during treatment with ranitidine (300 $\mathrm{mg}$ daily) were examined in a multicentre German study of 1923 patients with endoscopically proved, recurrent duodenal ulceration. Healing rates, per protocol, were $39.5 \%$ at two weeks, $\mathbf{7 0 . 9} \%$ at four weeks, and $93.2 \%$ at eight weeks. Prospective testing of five, predefined risk factors indicated that smoking $(p=0.0039)$ was associated with a decreased healing rate at two weeks. Frequent prior recurrence $(p=0.464)$, a heavy physical workload $(p=0 \cdot 145)$, and psychological stress $(p=0.062)$ were not associated with a decreased healing rate and there were too few patients at risk to allow assessment of the effect of regular NSAID intake. Exploratory analysis identified prior slow healing, a large ulcer, multiple ulcers, and prior ulcer complications, in addition to smoking, as markers of slow healing. In the absence of these risk factors, the mean healing time was 3.3 weeks (95\% confidence interval $3.0,3.5)$, rising to 3.7 weeks $(3.5,3.9)$ for one, $4 \cdot 4$ weeks $(4 \cdot 1,4 \cdot 7)$ for two, and $5 \cdot 1$ weeks $(4 \cdot 5$, 5.6) for three to five risk factors. Delayed duodenal ulcer healing is associated with multiple factors whose effect is cumulative; for patients with two or more of five easily identified risk factors, more than four weeks' treatment with a histamine $\mathrm{H}_{2}$ receptor antagonist is required to achieve ulcer healing.

(Gut 1993; 34: 1319-1326)
\end{abstract}

Risk factors for delayed duodenal ulcer healing are mentioned in all textbooks ${ }^{1-7}$ as important considerations in the management of duodenal ulcer disease. Despite numerous published reports, however, the most important risk factors associated with delayed ulcer healing are still undefined. It is also accepted that the presence of risk factors may affect the length of treatment required to effect healing but the optimal duration of treatment in the presence of specific risk factors has never been investigated.

There is, however, a number of obstacles to the identification of risk factors for slow healing. It is, of course, necessary to confirm ulcer diagnosis and healing at endoscopy, and since the expected changes in the healing rate are relatively small compared with changes due to ulcer treatment, it is essential that a large study population be examined to detect appropriate changes in the healing rate. If the study population is small, type II errors may occur. Even if the study population is large, however, the additional testing of multiple potential risk factors may result in both type I and type II errors. Interpretation may also be difficult if risk factors are examined in a protocol which comprises several treatment arms, since the effects of non-pharmacological factors may be obscured by a variety of treatment effects.

To minimise the problems outlined above, the risk factors for delayed ulcer healing were studied during the initial healing phase of a prospective, multicentre study (Recurrence of Ulcers of the Duodenal bulb: Epidemiology during Ranitidine treatment - RUDER) which was designed to enrol a minimum of 1280 patients suffering from endoscopically confirmed, recurrent duodenal ulceration. All patients received the same treatment until endoscopically confirmed healing had occurred. Ranitidine ( $300 \mathrm{mg}$ daily) was chosen since it is currently the most widely used ulcer treatment. On the basis of previous studies, five prospectively defined hypotheses were tested; namely, that smoking, a high prior duodenal ulcer recurrence rate, physical workload, mental stress, and intake of non-steroidal anti-inflammatory drugs (NSAIDs) are associated with delayed healing during ranitidine treatment. Additional potential risk factors for delayed healing were examined in a subsequent exploratory analysis.

\section{Methods}

\section{SELECTION OF HYPOTHESES}

At the outset, five hypotheses were selected prospectively on the grounds that they were refutable within the context of the study design, that they were of relevance to current duodenal ulcer research, or that they were of potential importance for both ulcer healing and ulcer recurrence. Specifically, the study tested the hypothesis that the duodenal ulcer healing rates after two weeks' treatment were lower in the presence of:

(1) A history of smoking, either currently or in the past;

(2) A high prior recurrence rate (two or more episodes of duodenal ulceration during the previous two years);

(3) A heavy physical workload;

(4) Psychological stress: patients were classified dichotomously by their physicians as unstressed or stressed (stressed at one or more follow up appointments);

(5) Regular intake of non-steroidal antiinflammatory drugs.

These factors were investigated since there 
are conflicting data regarding the effects of smoking, ${ }^{89}$ stress, ${ }^{11} 11$ previous duodenal ulcer recurrence rate, ${ }^{12}{ }^{13}$ and intake of NSAIDs ${ }^{14-16}$ on ulcer healing. In addition, it was postulated that the reported association of the latter two factors with ulcer relapse might result from changes in healing processes. ${ }^{17}$ The effect of a heavy physical workload was examined because epidemiological data suggest that this, and the associated high salt intake, may have been responsible for the high incidence of peptic ulceration early in the 20th century. ${ }^{18}$ Since only a limited number of hypotheses could be tested prospectively, other potential risk factors, such as a previous history of slow ulcer healing, ${ }^{19}$ were tested exploratorily either because it was not felt necessary to confirm their reported effect on healing or because they were considered to be less important to ulcer healing.

\section{SUBJECTS AND SELECTION CRITERIA}

Patients were recruited by 546 gastroenterologists at study centres throughout Germany starting in September 1986. Recruitment was stopped in March 1988, by which time 2109 patients had been enrolled. Participating gastroenterologists were asked to enrol eligible duodenal ulcer patients consecutively but none was permitted to enrol more than seven patients since the aim was to recruit patients over as short a time period as possible while ensuring that they were also drawn from many different parts of the country. Patients were recruited and followed 'en bloc' by the physician to maximise physician compliance. All subjects gave full, informed written consent to the study, which was conducted in accordance with the Declaration of Helsinki concerning studies in human subjects and was approved after submission to the study chairman's (ALB) local ethical committee at the Triemli Hospital, Zürich, Switzerland. The study was under the general direction of one author (ALB) with the assistance of three regional chairmen (RA, MC, HG) and 40 local medical supervisors. Day to day supervision was conducted by the IFNS (MF) who collected all documentation and examined it immediately. If documentation was incomplete, or if inspection by monitoring physicians showed inconsistencies, the treating physician was contacted at once by telephone (and if necessary by the local medical supervisor) to verify any discrepant or missing data.

Patients were invited to participate in the study if endoscopy confirmed an acute, uncomplicated duodenal ulcer greater than $5 \mathrm{~mm}$ in diameter, and if there was a history of at least one duodenal ulcer during the previous 12 months. Additional requirements were that the patients should be over 18 years of age, of fixed abode, and that they should have a prior history of good compliance with treatment. Patients were excluded from the study if they were pregnant or lactating, if they were expecting to undergo surgery, or if they had a history of concurrent gastric ulceration, renal insufficiency, alcoholism (pure ethanol intake greater than $100 \mathrm{ml} /$ day (women) or $120 \mathrm{ml} /$ day (men), or behaviour consistent with alcohol abuse), drug abuse, or language difficulties. Alcohol consumption, smoking, and salicylate or NSAID ingestion were not exclusion criteria and physicians were asked not to make specific recommendations with regard to these factors or to diet.

STUDY DESIGN AND PROTOCOL

At enrolment, endoscopic findings (number, size, and site of ulcers; presence of duodenitis and duodenal bulb deformity) and clinical findings (including height and weight) were recorded, as were the subject's ulcer symptoms (epigastric pain, burning, or fullness) and fitness; personal and family ulcer history; and social, occupational, past medical, drug, alcohol, and smoking histories. The number of duodenal ulcer episodes that had occurred during the previous two years was noted. Patients were deemed to have had prior slow healing if any previous ulcer had required a repeat course of treatment to effect healing. The physical arduousness of the patient's occupation was evaluated on a four point scale (light, moderate, heavy, and very heavy). NSAID intake was noted as either intermittent or regular at the time of the first endoscopy only. In addition, the physician made a personal assessment as to whether or not the patient seemed to be psychologically stressed at the time of the visit; the physician's evaluation of the patient's status was recorded as 'stressed' or 'unstressed'. The patient then received a two week supply of ranitidine $(300 \mathrm{mg}$, to be taken every evening after an early supper).

At the first, two week follow up appointment, endoscopy to assess ulcer healing was obligatory. At this, and all subsequent follow up appointments, the physician also noted concomitant illnesses and medical treatment and repeated his personal assessments of the patient's stress, symptom severity, fitness for work, and compliance with treatment. If the ulcer had healed, the patient started a maintenance regimen of ranitidine (150 mg at night) otherwise he or she was given an additional supply of ranitidine $(300 \mathrm{mg}$ at night). The timing of all subsequent follow up appointments and endoscopies in the healing phase was discretionary. The final information sheet for the healing phase was completed only when ulcer healing had been confirmed endoscopically, at which time the patient was transferred to the maintenance treatment regimen.

Overall, patients were deemed to be psychologically stressed if the physician had noted stress at any of the scheduled appointments. The data relating to the patients' dietary habits were collected after endoscopically confirmed ulcer healing in 985 patients to assess their habitual intake in relation to their normal physical activity, in the absence of active ulceration. Patients kept a detailed record of their food consumption over a three day period before their first follow up appointment in the maintenance phase of the study and also described their normal physical activity. An overall activity index (graded from 2 to 9) was then calculated on the basis of the patient's activity (graded from 1 (light) to 3 (heavy)) at work, during their free 
time and, where applicable, during sporting activity. Patients were classified into quartiles independently in respect of their energy intake and their physical activity and were then designated as having a low energy intake, a normal energy intake, or a high energy intake with respect to their physical activity.

\section{ENDOSCOPIC EVALUATION}

The endoscopic technique and associated sedation or anaesthesia were the responsibility of the treating physician, although, in each case, a full examination of the upper gastrointestinal tract was performed to exclude concomitant peptic disease in the oesophagus or stomach. A duodenal ulcer was defined as a mucosal defect of greater than $5 \mathrm{~mm}$ in diameter, measured by comparison with open biopsy forceps of known size. The number of ulcers, their site and shape, and any associated duodenitis, erosions, or complicating features such as scarring were noted. Ulcer healing was reported only if the defect had re-epithelialised completely; associated features, including residual erythema, oedema, friability, or deformation at or near the site of the healed ulcer were also noted.

\section{DATA AND STATISTICAL ANALYSIS}

Prospective analysis of two week healing rates

The proportion of ulcers healed after two weeks, in the presence and absence of the five prospectively defined risk factors, was assessed using Fisher's exact test: an alpha level of 0.05 , corrected to 0.01 according to Bonferroni to allow for multiple comparisons, was taken to indicate a significant difference in healing rates. These factors were also incorporated into a stepwise logistic regression model to identify independent risk factors (ACE method: Program PLR; BMDP Statistical Package Release 1987, Cork, Ireland).

\section{Exploratory analysis}

Differences in healing rates at two, four, and eight weeks were examined (Fisher's exact test) in the presence and absence of the following risk factors:

Multiple ulcers (two or more at the time of diagnosis);

Ulcer size (greater than $15 \mathrm{~mm}$ ) at entry into the study;

A history of prior slow ulcer healing;

A history of prior complications;

A history of prior ulcer haemorrhage;

A long history of ulcer disease (more than 10 years);

Duodenal bulb deformation at healing;

Excess dietary energy intake, coffee or tea consumption, wine, beer, spirits or alcohol consumption;

Concomitant disease;

Family history of ulcer disease;

Divorce;

Male gender;

Age (under 40 years old); and

Unemployment and immigrant worker status.
For factors associated with a significant change $(\mathrm{p}<0.05)$ in healing rate, odds ratios with $95 \%$ confidence intervals ${ }^{20}$ were calculated for healing rates at two, four, and eight weeks with regard to the individual risk factors and also in respect of all combinations of two of these risk factors. Factors were considered to be clinically relevant if, alone or in combination with another risk factor, they were associated with an increased odds ratio for delayed healing (lower $95 \%$ confidence limit greater than 1.00 ) at more than two time points. The mean times to ulcer healing were calculated for patients exposed to different risk factors, and the combined effects of the clinically relevant risk factors were assessed by calculating the two, four, and eight week healing rates and the mean times to healing in the presence of increasing numbers of risk factors.

\section{Results}

\section{PATIENT CHARACTERISTICS}

Between September 1986 and March 1988, 2109 patients were recruited for the study. Data were available for 1923 patients after $186(8 \cdot 8 \%)$ patients had been excluded for one or more of the following reasons: healing not documented (66 patients), patient's first ulcer (61), ulcer diameter less than $5 \mathrm{~mm}$ (39), supplementary

TABLE I Patient characteristics: social history and past medical history

\begin{tabular}{|c|c|}
\hline Social and medical history & $\mathrm{No}(\%)$ \\
\hline \multicolumn{2}{|l|}{ Gender ${ }^{\star}$ : } \\
\hline Male & $1318(68 \cdot 5)$ \\
\hline Female & $601(31 \cdot 3)$ \\
\hline \multicolumn{2}{|l|}{ Age: } \\
\hline $\begin{array}{l}<40 \mathrm{y} \\
\geqslant 40 \mathrm{y}\end{array}$ & $\begin{array}{r}587(30 \cdot 5) \\
1336(69 \cdot 5)\end{array}$ \\
\hline \multicolumn{2}{|l|}{ Marital status: } \\
\hline Married & $1444(75 \cdot 1)$ \\
\hline Common-law partner & $89(4 \cdot 6)$ \\
\hline Divorced & $131(6 \cdot 8)$ \\
\hline Widowed & $85(4 \cdot 4)$ \\
\hline Single & $174(9 \cdot 0)$ \\
\hline \multicolumn{2}{|l|}{ Work statust: } \\
\hline Employed & $1158(60 \cdot 2)$ \\
\hline Self employed & $164(8 \cdot 5)$ \\
\hline Retired & $268(13.9)$ \\
\hline Unemployed & $90(4 \cdot 7)$ \\
\hline \multicolumn{2}{|l|}{ Physical work $\ddagger$ : } \\
\hline Light & $814(42 \cdot 3)$ \\
\hline Medium & $802(41 \cdot 7)$ \\
\hline Heavy/very heavy & $224(11 \cdot 2)$ \\
\hline \multicolumn{2}{|c|}{ Dietary energy intake in relation to physical activity $\$:$ : } \\
\hline Low/appropriate & $737(74 \cdot 8)$ \\
\hline High & $248(25 \cdot 2)$ \\
\hline \multicolumn{2}{|l|}{ Smoking: } \\
\hline Non-smokers & $464(24 \cdot 1)$ \\
\hline Ex-smokers & $431(22 \cdot 4)$ \\
\hline Current smokers & $1028(53 \cdot 5)$ \\
\hline \multicolumn{2}{|l|}{ Alcohol: } \\
\hline Teetotal & $804(41 \cdot 8)$ \\
\hline Alcohol consumed & $1119(58 \cdot 2)$ \\
\hline Beer & $949(49 \cdot 3)$ \\
\hline Wine & $320(16 \cdot 6)$ \\
\hline Spirits & $231(12 \cdot 0)$ \\
\hline \multicolumn{2}{|l|}{ Stimulants: } \\
\hline Coffee & $1455(75 \cdot 5)$ \\
\hline Tea & $860(44 \cdot 7)$ \\
\hline Cola & $223(11 \cdot 6)$ \\
\hline \multicolumn{2}{|l|}{ Psychological stress: } \\
\hline Yes & $1183(61 \cdot 5)$ \\
\hline No & $740(38 \cdot 5)$ \\
\hline \multicolumn{2}{|l|}{ Concomitant illness: } \\
\hline $\begin{array}{l}\text { Yes } \\
\text { No }\end{array}$ & $\begin{array}{r}638(33 \cdot 2) \\
1285(66 \cdot 8)\end{array}$ \\
\hline \multicolumn{2}{|l|}{ NSAID intake: } \\
\hline Regular & $12(0 \cdot 62)$ \\
\hline Intermittent & $102(5 \cdot 3)$ \\
\hline No & $1809(94 \cdot 1)$ \\
\hline
\end{tabular}

Data available for $\star 1919,+1680, \ddagger 1840$, and $\$ 985$ patients; otherwise data available for all 1923 patients. 


\begin{tabular}{|c|c|c|}
\hline & $\begin{array}{l}\text { TABLE II Patient characte } \\
\text { endoscopic findings }\end{array}$ & \\
\hline & Ulcer history +endoscopy & $\mathrm{No}(\%)$ \\
\hline & $\begin{array}{l}\text { History } \\
\text { Relapses in prior } 2 \mathrm{y} \text { : } \\
\quad 1 \\
2 \\
3 \\
4 \\
5 \text { or more }\end{array}$ & $\begin{array}{l}239(12 \cdot 4) \\
474(24 \cdot 7) \\
434(22 \cdot 6) \\
431(22 \cdot 4) \\
345(17 \cdot 9)\end{array}$ \\
\hline & $\begin{array}{l}\text { Prior slow healing: } \\
\text { Yes } \\
\text { No } \\
\text { Unknown }\end{array}$ & $\begin{array}{r}705(36 \cdot 7) \\
1204(62 \cdot 6) \\
14(0 \cdot 7)\end{array}$ \\
\hline & $\begin{array}{l}\text { Prior complications: } \\
\text { Perforation } \\
\text { Haemorrhage } \\
\text { Outlet obstruction } \\
\text { Others }\end{array}$ & $\begin{array}{c}38(2 \cdot 0) \\
296(15 \cdot 4) \\
78(4 \cdot 1) \\
23(1 \cdot 2)\end{array}$ \\
\hline & $\begin{array}{l}\text { Disease duration }(\mathrm{y}): \\
\quad<10 \\
\quad \geqslant 10\end{array}$ & $\begin{array}{r}1006(55 \cdot 5) \\
805(44 \cdot 5)\end{array}$ \\
\hline & $\begin{array}{l}\text { Family history of ulcer*: } \\
\text { Yes } \\
\text { No }\end{array}$ & $\begin{array}{r}759(39 \cdot 5) \\
1154(60 \cdot 5)\end{array}$ \\
\hline & $\begin{array}{l}\text { Ulcer symptoms: } \\
\text { Frequent } \\
\text { Infrequent } \\
\text { No } \\
\text { Unknown } \\
\text { Improved by food } \\
\text { Worsened by food }\end{array}$ & $\begin{array}{c}1795(93 \cdot 3) \\
103(5 \cdot 4) \\
24(1 \cdot 2) \\
1(0 \cdot 1) \\
1347(70 \cdot 0) \\
247(12 \cdot 8)\end{array}$ \\
\hline & $\begin{array}{l}\text { Endoscopy } \\
\text { No of ulcers: } \\
1 \\
2 \\
3 \\
4 \\
5 \text { or more } \\
\text { Greatest ulcer diameter }(\mathrm{mm}) \text { : }\end{array}$ & $\begin{array}{c}1623(84 \cdot 4) \\
253(13 \cdot 2) \\
32(1 \cdot 7) \\
7(0 \cdot 4) \\
8(0 \cdot 4)\end{array}$ \\
\hline & $\begin{array}{l}\text { Greatest ulcer diameter }(\mathrm{mm}): \\
5-10\end{array}$ & $1063(55 \cdot 3)$ \\
\hline $\begin{array}{l}\text { Figure 1: Time course of the } \\
\text { study with the initial }\end{array}$ & $\begin{array}{l}10-15 \\
>15\end{array}$ & $\begin{array}{l}729(37 \cdot 9) \\
131(6 \cdot 8)\end{array}$ \\
\hline $\begin{array}{l}\text { diagnostic endoscopy and the } \\
\text { start of ranitidine therapy at }\end{array}$ & $\begin{array}{l}\text { Deformed bulb at healing: } \\
\text { Yes } \\
\text { No }\end{array}$ & $\begin{array}{r}1221(63 \cdot 5) \\
702(36 \cdot 5)\end{array}$ \\
\hline
\end{tabular}
23 patients were excluded because they did not fulfil the entry criteria; data were not available for another 63 patients who were not followed to healing. The first endoscopy after two weeks' therapy was obligatory; the time of subsequent endoscopies was at the discretion of the treating physician. The cumulative number of patients with healed ulcers is shown at the right; the number of patient who did not complete the study and the reasons are shown on the left.

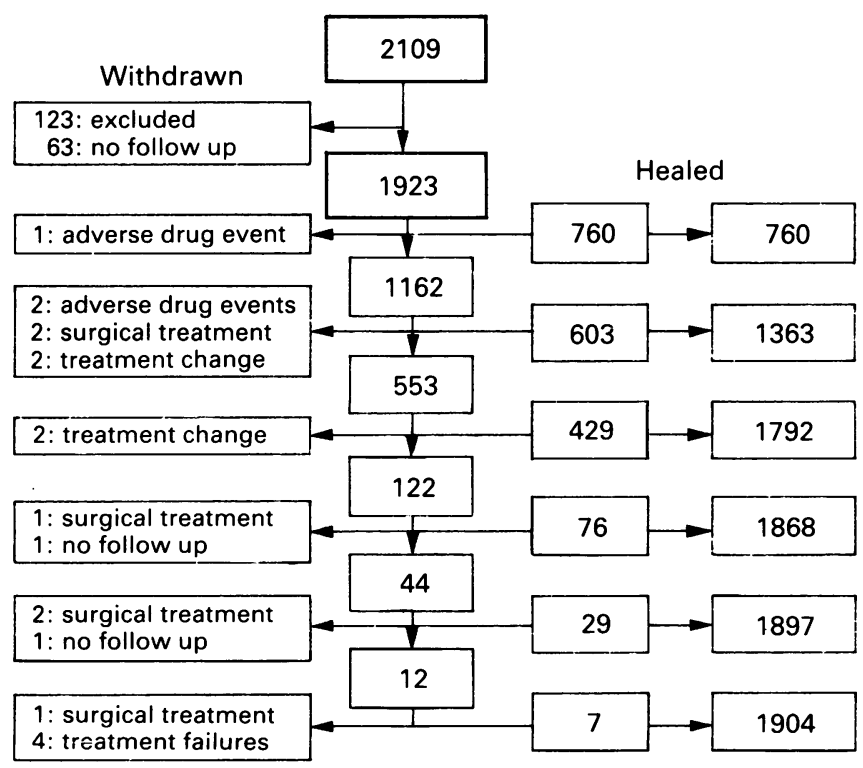

previous two years. Mean body weight was $73 \mathrm{~kg}$ (SD 12) and mean height was $172 \mathrm{~cm}$ (SD 8). Other patient characteristics and details of their past ulcer history and findings at the diagnostic endoscopy are summarised in Tables I and II, respectively. The time course of the study protocol (Fig 1) indicates when ulcer healing was confirmed or when the patient was withdrawn from the protocol for other reasons.

PATIENT SYMPTOMS AND DIETARY INTAKE

At the time of diagnosis, $1819(94.5 \%)$ patients had typical ulcer symptoms and 1513 patients $(78 \cdot 7 \%)$ experienced symptoms when fasted. Symptoms during fasting were more common in patients who had a high dietary energy intake in relation to their physical activity $(83.9 \%$, $\mathrm{p}=0.0010$ ) than in patients who had a low or appropriate intake $(73.8 \%)$. Eating led to improved ulcer symptoms in $76.6 \%$ of patients who had a high intake compared with only $67 \cdot 8 \%$ $(p=0.0102)$ of patients who had a low or appropriate dietary energy intake. An exacerbation of symptoms by eating was comparably frequent in patients whose dietary energy intakes were high $(12.9 \%)$ and low or appropriate $(15.5 \%, \mathrm{p}=$ $0.3537)$ in respect of their physical activity.

PATIENT MOTIVATION AND COMPLIANCE

Physicians reported that 1457 patients $(75 \cdot 8 \%)$ were highly motivated and that a further 356 $(18 \cdot 5 \%)$ were well motivated despite initial reservations at enrolment. Fifty $(2 \cdot 6 \%)$ patients were poorly motivated and information was lacking for another $60(3 \cdot 1 \%)$. At the two week obligatory endoscopy, $1887(98 \cdot 1 \%)$ of the 1923 patients had taken their medication regularly, 29 (1.5\%) had taken their medication irregularly, one had stopped medication because of side effects, and information was lacking for the remaining six $(0.3 \%)$ patients. At the final endoscopy, $934(97 \cdot 1 \%)$ of the 962 patients whose duodenal ulcers had not healed at the two week endoscopy had taken their medication regularly, $15(1 \cdot 6 \%)$ had taken medication irregularly, and information was lacking for $13(1 \cdot 4 \%)$ patients.

\section{ADVERSE DRUG EVENTS}

Potential side effects were noted by $47(2 \cdot 2 \%)$ patients, some of whom reported several symptoms concurrently. The most common symptoms were headache (seven patients), constipation (six), dry mouth (five), impotence or decreased libido (five), hair loss (four), diarrhoea (four), and pruritus (four). Other symptoms including tiredness, exanthemata, and vertigo were noted, although none was reported by more than three patients. Side effects necessitated stopping treatment in three patients after three, 14 , and 21 days, respectively.

Week 12

Week 24

OVERALL HEALING RATES

The mean duration of ranitidine therapy was four weeks (SD 3 weeks). A per protocol analysis Final showed that two, four, and eight week healing rates were $39 \cdot 5 \%$ (760 patients), $70.9 \%$ (1363 
TABLE III Healing rates at two weeks in presence of prospectively defined risk factors

\begin{tabular}{|c|c|c|c|c|c|}
\hline \multirow[b]{2}{*}{ Risk factor } & \multirow{2}{*}{$\begin{array}{l}\text { No in } \\
\text { group }\end{array}$} & \multirow{2}{*}{$\begin{array}{l}\text { No healed } \\
(\%)\end{array}$} & \multirow[b]{2}{*}{ pvalue ${ }^{\star}$} & \multicolumn{2}{|c|}{ Stepwise p valuet } \\
\hline & & & & Step 1 & Step 2 \\
\hline \multicolumn{6}{|l|}{ Smoking: } \\
\hline $\begin{array}{l}\text { Smoker/ex-smoker } \\
\text { Non-smoker }\end{array}$ & $\begin{array}{r}1459 \\
464\end{array}$ & $\begin{array}{l}550(37 \cdot 7) \\
210(45 \cdot 3)\end{array}$ & 0.0039 & 0.0008 & $0 \cdot 0008 \ddagger$ \\
\hline \multicolumn{6}{|l|}{ Prior frequent recurrence: } \\
\hline $\begin{array}{l}>1 \text { in } 2 y \\
1 \text { in } 2 y\end{array}$ & $\begin{array}{r}1684 \\
239\end{array}$ & $\begin{array}{l}659(39 \cdot 1) \\
101(42 \cdot 3)\end{array}$ & 0.359 & $0 \cdot 464$ & 0.518 \\
\hline \multicolumn{6}{|l|}{ Physical workload: } \\
\hline $\begin{array}{l}\text { Heavy/very heavy } \\
\text { Light/medium }\end{array}$ & $\begin{array}{r}224 \\
1616\end{array}$ & $\begin{array}{l}100(44 \cdot 6) \\
639(39 \cdot 5)\end{array}$ & $0 \cdot 147$ & $0 \cdot 145$ & 0.0637 \\
\hline \multicolumn{6}{|l|}{ Psychological stress: } \\
\hline $\begin{array}{l}\text { Stressed } \\
\text { Not stressed }\end{array}$ & $\begin{array}{r}1183 \\
740\end{array}$ & $\begin{array}{l}448(37 \cdot 9) \\
312(42 \cdot 2)\end{array}$ & 0.062 & $0 \cdot 0767$ & $0 \cdot 147$ \\
\hline \multicolumn{6}{|l|}{ NSAID intake: } \\
\hline $\begin{array}{l}\text { Yes } \\
\text { No }\end{array}$ & $\begin{array}{r}114 \\
1809\end{array}$ & $\begin{array}{r}46(40 \cdot 3) \\
714(39 \cdot 5)\end{array}$ & $0 \cdot 844$ & $0 \cdot 766$ & $0 \cdot 815$ \\
\hline
\end{tabular}

^Fisher's exact test (two sided); †stepwise logistic regression analysis: each p value is the result of a two sided $F$ test; $\ddagger$ the relevant variable had been incorporated into the model.

patients), and $93.2 \%$ (1792 patients) respectively. After an 'intent to treat' analysis, the healing rates at two, four, and eight weeks were $38 \cdot 3 \%, 68 \cdot 6 \%$, and $90 \cdot 2 \%$ respectively. These latter results exclude data from 34 patients with index ulcers less than $5 \mathrm{~mm}$ in diameter who had cumulative two, four, and eight week healing rates of $41 \cdot 2 \%, 73 \cdot 5 \%$, and $97 \cdot 1 \%$ respectively and 54 patients suffering from their first ulcer for whom the equivalent healing rates were $50 \%$, $74 \cdot 1 \%$, and $94 \cdot 4 \%$.

By eight weeks, three patients had been withdrawn because of adverse drug side effects while four had been transferred to other medical treatment and two had undergone surgery because of increasing pain or ulcer size. By the end of the healing phase, $19(0.99 \%)$ of the 1923 patients who had fulfilled the entry criteria had failed to heal: the time to healing was 12 weeks in 76 patients $(3.95 \%), 24$ weeks in 29 patients $(1.51 \%)$, and greater than 24 weeks in seven patients $(0 \cdot 36 \%)$. After eight weeks, a further four patients eventually underwent surgery for failure to heal, two were lost to follow up, and four were deemed to have resistant ulcers (Fig 1).

\section{PROSPECTIVE ANALYSIS}

Of the five prospectively defined risk factors, only smoking was associated with a significant increase in the proportion of slow healers after both univariate and stepwise logistic regression analyses (Table III). Smoking was also associated with a decreased healing rate at four and eight weeks (Fig 2) but neither frequent prior recurrences (four week healing: $71 \cdot 3 \%$, eight week healing: $93 \cdot 3 \%$ ), a heavy physical workload (four week healing: $71.4 \%$, eight week healing: 93.3\%), psychological stress (four week healing: $71 \cdot 2 \%$, eight week healing: $93 \cdot 0 \%$ ) nor NSAID intake (four week healing: $64.9 \%$, eight week healing: $90 \cdot 4 \%$ ) was associated with a difference in healing rates.

The two week healing rates for patients with one, two, three, four, and five or more recurrences during the previous two years were $42 \cdot 3 \%, 40.5 \%, 40 \cdot 6 \%, 34.6 \%$, and $40.6 \%$ respectively. Twelve patients took NSAIDs regularly: the proportion with healed ulcers at two weeks (four of 12), four weeks (seven of 12), and eight weeks (10 of 12) did not differ signific- antly from the proportion of intermittent NSAID takers with healed ulcers at two (42 of $102 ; \mathrm{p}-0.76 v$ regular intake), four (67 of $102 ; \mathrm{p}-0.75)$, and eight (93 of $102 ; \mathrm{p}=0.33$ ) weeks.

\section{DESCRIPTIVE ANALYSIS OF ADDITIONAL RISK} FACTORS

\section{Effect of individual risk factors}

Exploratory analysis showed another nine risk factors associated with slow healing (Fig 2). Prior slow healing was associated with decreased two, four, and eight week healing rates while ulcers greater than $15 \mathrm{~mm}$ in diameter and multiple ulcers were associated with decreased healing rates at two and four weeks. Slow healing was also seen: (1) at two weeks in association with prior complications, unemployment, a deformed duodenal bulb at healing, and an excessive dietary intake; (2) at four weeks in association with divorce; and (3) at eight weeks in association with abstention from wine. Of the 10 risk factors associated with delayed healing, ulcers larger than $15 \mathrm{~mm}$, smoking, multiple ulcers, and prior slow healing were associated with odds ratios for delayed healing which were significantly greater than 1.00 at two or more time points (Fig 2). The following risk factors were not associated with a decreased healing rate at two, four, or eight weeks respectively: male gender $(38.5 \%, 69.6 \%, 93.2 \%)$; age under 40 years (39.5\%, 72.9\%, 93.9\%); alcohol (40.1\%, 71.9\%, $93.7 \%)$; beer $(39.5 \%, 70.7 \%, 92.9 \%)$; spirits $(39 \cdot 8 \%, 71 \cdot 4 \%, 95 \cdot 2 \%)$; coffee $(38 \cdot 4 \%, 71 \cdot 3 \%$, $93.8 \%)$; tea $(40.8 \%, 69 \cdot 8 \%, 93.4 \%)$; a family history of duodenal ulcer disease $(37 \cdot 8 \%, 68 \cdot 9 \%$, $93.3 \%)$; prior ulcer haemorrhage $(34.8 \%$, $68.9 \%, 94 \cdot 2 \%$ ); concomitant illness (37.5\%, $68.5 \%, 92 \cdot 8 \%)$; immigrant worker status $(37 \cdot 5 \%, 70 \cdot 5 \%, 92 \cdot 1 \%)$; shift work $(36 \cdot 5 \%$, $73.0 \%, 93.8 \%$ ); or a history of ulcer disease for more than 10 years $(39 \cdot 3 \% .68 \cdot 0 \%, 91 \cdot 9 \%)$.

\section{Effect of combinations of risk factors}

Risk factors identified by univariate analysis were examined in pairs to determine their effect on healing. Specific combinations of two risk factors associated with delayed healing were:

Prior slow healing plus smoking (two week healing: $29 \cdot 7 \%$, odds ratio $1 \cdot 82$ (95\% confidence interval $1 \cdot 47,2 \cdot 26$ ); four week healing: $61 \cdot 6 \%$, $1 \cdot 85(1 \cdot 49,2 \cdot 26)$; eight week: $89 \cdot 2 \%, 2 \cdot 23(1 \cdot 53$, 3.24));

Prior slow healing plus ulcer $>15 \mathrm{~mm}$ (two week healing: $28 \cdot 1 \%, 1 \cdot 70(0 \cdot 949,3 \cdot 07)$; four week healing: $53 \cdot 1 \%, 2 \cdot 21(1 \cdot 30,3 \cdot 76)$; eight week healing: $87 \cdot 5 \%, 2 \cdot 02(0 \cdot 867,4 \cdot 51))$;

Prior slow healing plus prior complications (two week healing: $26.8 \%, 1.90(1.36,2.66)$; four week healing: $60.5 \%, 1.69(1.24,2.30)$; eight week healing: $90.3 \%, 1.57(0.919,2.64))$;

Prior slow healing plus multiple ulcers (two week healing: $23.2 \%, 2.27(1.46,3.55)$; four week healing: $56.8 \%, 1.94(1.32,2 \cdot 85)$; eight week healing: $88 \cdot 0 \%, 1.98(1 \cdot 07,3 \cdot 60)$;

Smoking plus multiple ulcers (two week healing: $27 \cdot 7 \%, 1 \cdot 82(1 \cdot 32,2 \cdot 51)$; four week healing: 

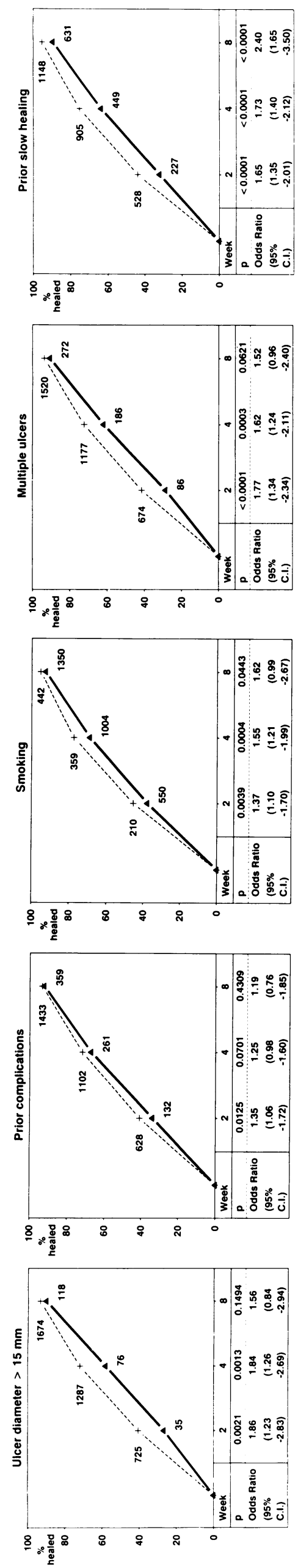
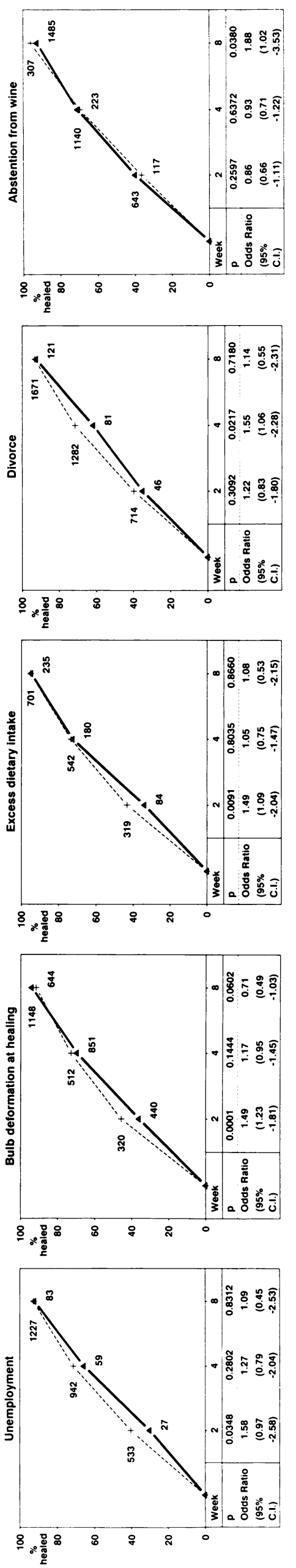

$61 \cdot 8 \%, 1 \cdot 59(1 \cdot 18,2 \cdot 15)$; eight week healing: $90.5 \%, 1.53(0.908,2.55))$;

Ulcer $>15 \mathrm{~mm}$ plus prior complications (two week healing: $24.0 \%, 2 \cdot 11(1 \cdot 06,4 \cdot 29)$; four week healing: $50.0 \%, 2.50(1.38,4.55)$; eight week healing: $82 \cdot 0 \%, 3 \cdot 15(1 \cdot 39,6 \cdot 93))$.

Thus, smoking, an ulcer diameter greater than $15 \mathrm{~mm}$, prior slow healing, multiple ulcers, and prior complications were considered to be clinically relevant risk factors for slow healing since, alone or in combination with another risk factor, they were associated with decreased healing rates at two or more of the two, four, and eight week assessment points. The effect of these risk factors was cumulative. Patients with none of the five risk factors had a four week healing rate of $82 \cdot 7 \%(95 \% \mathrm{CI} 77 \cdot 7,87 \cdot 7 \%)$ whereas those with two of the five risk factors had four week healing rates ranging from $50 \cdot 0 \%$ to $64.9 \%$ (Table IV). Patients with one, two, and three or more of the risk factors had progressively lower two, four, and eight week healing rates regardless of which specific factors were present (Fig 3).

\section{Effect of risk factors on time to healing}

Overall, the mean time to ulcer healing was $4 \cdot 1$ weeks $(95 \%$ CI $4 \cdot 0,4 \cdot 2)$. The mean times to healing were prolonged in patients with an ulcer greater than $15 \mathrm{~mm}$ in diameter $(5.0$ weeks; $95 \%$ CI $4 \cdot 3,5 \cdot 7)$, prior slow healing ( $4 \cdot 7$ weeks; $95 \%$ CI $4 \cdot 4,5 \cdot 0)$, multiple ulcers $(4 \cdot 8$ weeks; $95 \%$ CI $4 \cdot 4,5 \cdot 2)$, prior complications $(4 \cdot 4$ weeks; $95 \%$ CI $4 \cdot 0,4 \cdot 8)$, and smoking $(4 \cdot 2$ weeks; $95 \%$ CI $4 \cdot 0,4 \cdot 4)$ compared with a mean healing time of $3 \cdot 3$ weeks $(95 \% \mathrm{CI} 3 \cdot 0,3 \cdot 5)$ in patients with none of these risk factors. The effect of the risk factors on the time to healing was cumulative: patients with one, two, and three or more risk factors needed progressively longer courses of treatment to achieve ulcer healing (Fig 3). Overall, patients with two risk factors took longer to heal $(4 \cdot 4$ weeks; $95 \%$ CI $4 \cdot 1,4 \cdot 7)$ than did those with only one risk factor $(3.7$ weeks; $95 \%$ CI $3.5,3.9)$; this was true for all pairs of risk factors with the exception of multiple ulcers plus prior complications and multiple ulcers plus an ulcer greater than $15 \mathrm{~mm}$ in diameter (Table IV), which were associated with prolonged healing only in comparison with an absence of risk factors.

\section{Discussion}

In the present study, smoking was associated with a decreased duodenal ulcer healing rate at two, four, and eight weeks; no other predefined risk factor - frequent prior recurrences, heavy

Figure 2: Two, four, and eight week healing rates in the presence and absence of the 10 risk factors which were shown to be associated with delayed healing. The solid line with filled triangles indicates the healing rate in the presence of the specified risk factor and the dashed line with crosses indicates the healing rate in the absence of the risk factor: figures within each plot show the absolute number of patients healed in each group. The tables below each plot list the result of Fisher's exact test in examining the difference in healing rates in the presence and absence of each risk factor at two, four, and eight weeks with the respective odds ratios and $95 \%$ confidence intervals. 
TABLE IV Mean times to healing and healing rates after four weeks' treatment for specific combinations of two risk factors

\begin{tabular}{|c|c|c|c|c|c|}
\hline & $\begin{array}{l}\text { Ulcer } \\
>15 \mathrm{~mm}\end{array}$ & $\begin{array}{l}\text { Prior slow } \\
\text { healing }\end{array}$ & $\begin{array}{l}\text { Multiple } \\
\text { ulcers }\end{array}$ & $\begin{array}{l}\text { Prior } \\
\text { complication }\end{array}$ & \\
\hline \multirow[t]{4}{*}{ Smoking } & $\begin{array}{l}5 \cdot 1 \\
(4 \cdot 2,6 \cdot 0) \\
58 \% \\
(48,68) \\
99\end{array}$ & $\begin{array}{l}4 \cdot 7 \\
(4 \cdot 4,5 \cdot 0) \\
62 \% \\
(58,66) \\
556\end{array}$ & $\begin{array}{l}4 \cdot 8 \\
(4 \cdot 3,5 \cdot 3) \\
62 \% \\
(55,68) \\
219\end{array}$ & $\begin{array}{l}4 \cdot 4 \\
(4 \cdot 0,4 \cdot 8) \\
67 \% \\
(61,72) \\
296\end{array}$ & $\begin{array}{l}\text { Weeks to healing } \\
\text { (95\% CI) } \\
\text { Healing at four } \\
\text { weeks }(95 \% \mathrm{CI}) \\
\text { No }\end{array}$ \\
\hline & \multirow[t]{3}{*}{$\begin{array}{l}\text { Ulcer } \\
>15 \mathrm{~mm}\end{array}$} & $\begin{array}{l}5 \cdot 4 \\
(4 \cdot 3,6 \cdot 5) \\
53 \% \\
(41,65) \\
64\end{array}$ & $\begin{array}{l}5 \cdot 5 \\
(3 \cdot 6,7 \cdot 4) \\
54 \% \\
(35,72) \\
28\end{array}$ & $\begin{array}{l}5 \cdot 6 \\
(4 \cdot 4,6 \cdot 8) \\
50 \% \\
(36,64) \\
49\end{array}$ & $\begin{array}{l}\text { Weeks to healing } \\
(95 \% \text { CI) } \\
\text { Healing at four } \\
\text { weeks }(95 \% \text { CI }) \\
\text { No }\end{array}$ \\
\hline & & \multirow[t]{2}{*}{$\begin{array}{l}\text { Prior slow } \\
\text { healing }\end{array}$} & $\begin{array}{l}5 \cdot 2 \\
(4 \cdot 4,6 \cdot 0) \\
57 \% \\
(48-66) \\
124\end{array}$ & $\begin{array}{l}4 \cdot 9 \\
(4 \cdot 3,5 \cdot 5) \\
61 \% \\
(54-67) \\
203\end{array}$ & $\begin{array}{l}\text { Weeks to healing } \\
(95 \% \mathrm{CI}) \\
\text { Healing at four } \\
\text { weeks }(95 \% \mathrm{CI}) \\
\text { No }\end{array}$ \\
\hline & & & $\begin{array}{l}\text { Multiple } \\
\text { ulcers }\end{array}$ & $\begin{array}{l}5 \cdot 0 \\
(3 \cdot 8,6 \cdot 2) \\
65 \% \\
(54.76) \\
77\end{array}$ & $\begin{array}{l}\text { Weeks to healing } \\
(95 \% \mathrm{CI}) \\
\text { Healing at four } \\
\text { weeks }(95 \% \mathrm{CI}) \\
\text { No }\end{array}$ \\
\hline
\end{tabular}

physical work, psychological stress, or NSAID ingestion - affected the healing rate. Exploratory analysis identified nine other risk factors: prior slow healing was associated with decreased healing rates at two, four, and eight weeks but the remainder - multiple ulcers, a large ulcer, prior complications, unemployment divorce, excess dietary energy intake in relation to physical activity, abstention from wine, and a deformed duodenal bulb at the time of healing - had less prolonged effects. Five risk factors, alone or in combination, were associated with a lower healing rate at two or more assessment times and were, therefore, considered to be clinically important; these factors - smoking, large ulcer, prior slow healing, multiple ulcers, and prior complications - had a cumulative effect on ulcer healing.

Most risk factors sought in previous studies were also examined in the present study, with the notable exceptions of Helicobacter pylori infection, ${ }^{21}$ gastric acid secretion, ${ }^{1322}$ pepsinogen ${ }^{23-25}$ gastrin, ${ }^{2426}$ and blood group. ${ }^{242627}$ In general, these factors were omitted because they are not examined routinely in ulcer patients. $H$ pylori was not examined because its importance in duodenal ulcer disease was not widely
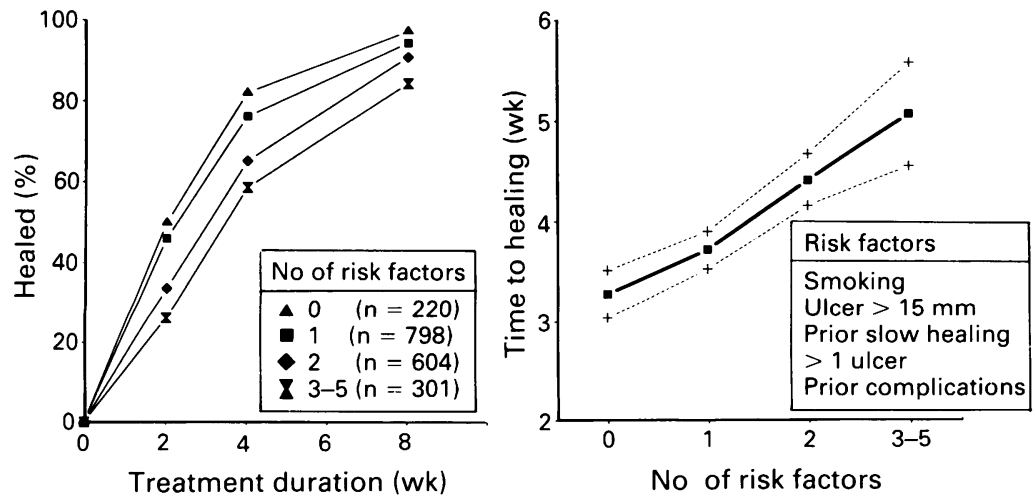

Figure 3: Left panel-two, four, and eight week healing rates in subjects with zero, one, two, and three to five of the following risk factors: smoking, ulcer greater than $15 \mathrm{~mm}$ in diameter, prior slow healing, multiple ulcers, and prior complications. Right panel-the mean time to ulcer healing in subjects with zero, one, two, and three to five risk factors: the thick line indicates the mean time to healing, the thinner dashed lines indicate the upper and lower $95 \%$ confidence intervals for the mean. recognised when this study was being planned. However, since only $12 \%$ of the duodenal ulcer patients in a parallel, multicentre German study were $H$ pylori negative and since, furthermore, neither the presence nor the density of $H$ pylori colonisation affected ulcer healing, ${ }^{28}$ it is unlikely that $H$ pylori would have emerged as a risk factor for delayed healing in the present study. The mechanisms whereby smoking influences ulcer healing are unknown; it probably does not affect gastric acidity, ${ }^{29}$ although it may alter duodenal motility $^{30}$ and acidity. ${ }^{31}$ Healing rates in exsmokers who stopped smoking at least one month before the start of treatment, however, are similar to those in smokers, ${ }^{32}$ suggesting that smoking also has an indirect effect, associated perhaps with specific behaviour or personality characteristics. The increased healing rate in wine drinkers is consistent with other reports that moderate alcohol intake may be harmless ${ }^{33}$ or beneficial. ${ }^{103435}$ The association between duodenal deformation and slow healing cannot be equated with previous reports ${ }^{136}$ since deformation in this study was noted after healing. Thus, scarring may have been the result, rather than the cause, of slow healing. The decreased healing rate associated with excess dietary intake, assessed after ulcer healing, may indicate that food alleviates ulcer symptoms or that it slows healing by stimulating acid secretion. Food intake must be evaluated during healing to test these hypotheses.

Many previous studies have sought risk factors retrospectively in the context of trials designed primarily to detect a difference between antiulcer treatments. In these studies, multiple treatment variables with relatively few patients in each risk factor group have precluded detection of changes in the healing rate associated with non-pharmacological risk factors whose effects are usually smaller than those due to ulcer therapy. The present study was therefore designed to recruit a large number of patients, all of whom received the same treatment, allowing unequivocal refutation of the prospectively defined hypotheses that a heavy physical workload and a high prior recurrence rate are associated with a decreased healing rate. Although stress (assessed dichotomously by the physician) was not associated with slow healing, closer analysis of the data showed that continuous, but not intermittent, stress was associated with slow healing. ${ }^{37} \mathrm{~A}$ deleterious effect of regular NSAID intake on ulcer healing cannot be excluded since there were few patients at risk. Indeed, there were fewer patients than expected taking NSAIDs, perhaps since intake had been reduced because of chronic duodenal ulcer disease. That said, the prevalence of NSAID intake was not significantly lower than that reported in an Australian community prevalence study $^{38}$ after correction for a lower proportion of women in the present study.

The clinical relevance of the risk factors identified by exploratory statistical testing in the present study should be confirmed in future, prospective studies of appropriate size but factors which were found not to be associated with slow healing can be presumed to be clinically unimportant. In the present study, five risk 
factors were considered to be clinically relevant because they were associated, at a minimum of two assessment points, with a decreased healing rate. The effect of these factors was cumulative in that the proportion of patients unhealed at each time point and the mean time to healing increased progressively with the number of risk factors to which the patient was exposed.

The data from this study confirm that nonpharmacological factors are important determinants of duodenal ulcer healing during treatment with a histamine $\mathrm{H}_{2}$ receptor antagonist and that healing processes are affected by multiple factors whose effects are cumulative. With the exception of smoking, the most important risk factors identified in this study are markers of a diathesis for slow healing and are not amenable to modification. Furthermore, although smoking habits can be modified, this may not affect ulcer healing since the healing rate in ex-smokers was comparable with that in patients who continued to smoke. ${ }^{32}$ Thus, the main purpose of identifying these risk factors in clinical practice is to allow the physician to decide which patients will require more prolonged or more potent ulcer treatment. On the basis of the present study, patients with two or more of the following risk factors - prior slow healing, smoking, a large ulcer, prior complications, and multiple ulcers should receive treatment with a histamine $\mathrm{H}_{2}$ receptor antagonist for more than four weeks.

These data were presented in part at the 90th Annual Meeting of the American Gastroenterological Association in Washington, DC (Gastroenterology 1989; 96: A47).

(Gastroenterology 1989; 96: A47). $32-26369.89$ and a grant from Cascan GmbH \& Co KG, Wiesbaden, Germany.

1 Isenberg JI, McQuaid KR, Laine L, Rubin W. Acid peptic disorders. In: Yamada T, ed. Textbook of Gastroenterology. Philadelphia, New York, London, Hagerstown: Lippincott, 1991: Vol 1; 1241-352.

2 Soll AH. Duodenal ulcer and drug therapy. In: Sleisenger MH, Fordtran JS, eds. Gastrointestinal disease: pathophysiology, diagnosis and management. 4th Ed. Philadelphia: physiology, diagnosis and manage

3 Colin-Jones DG. Medical treatment of peptic ulcer. In Misiewicz JJ, Pounder RE, Venables CW, eds. Disease of th gut and pancreas. Oxford: Blackwell Scientific, 1987: 288-

4 Thomson ABR, Mahachai V. Medical management of uncomplicated peptic ulcer disease. In: Berk JE, Haubrich WS, Kalser MH, Roth JLA, Schaffner F, eds. Bockus gastroenterology. 4th Ed. Philadelphia: WB Saunders, 1985: 1116-54.

5 Shearman DJC, Finlayson NDC, Carter DC. Peptic ulceration. In: Diseases of the gastrointestinal tract and liver. 2nd $\mathrm{Ed}$ Edinburgh: Churchill Livingstone, 1989: 201-54.

6 McGuigan JE. Peptic ulcer. In: Isselbacher KJ, Adams RD, Braunwald E, Petersdorf RG, Wilson JD, eds. Harrison's principles of internal medicine. 9th Ed. Tokyo: McGraw-Hill, principles of interna

7 Andreoli TE, Carpenter CCJ, Plum F, Smith LR Jr. Acid peptic disease. In: Cecil Essentials of medicine. Philadelphia WB Saunders, 1986: 293-300.

8 Korman MG, Hansky J, Merrett AC, Schmidt GT. Ranitidine in duodenal ulcer. Incidence of healing and effect of smoking. Dig Dis Sci 1982; 27: 712-5.

9 Lee FI, Reed PI, Crowe JP, McIsaac RL, Wood JR. Acute treatment of duodenal ulcer: a multicentre study to compare ranitidine $150 \mathrm{mg}$ twice daily with ranitidine $300 \mathrm{mg}$ once at night. Gut 1986; 27 : 1091-5.

10 Bertschinger P, Lacher G, Aenishaenslin W, Baerlocher C Bernouilli R, Egger G, et al. Presenting characteristics of patients with duodenal ulcer and outcome of medical treatment in controlled clinical trials using cimetidine and diethylamine persilate to treat ulcer attack and diethylamine persilate and placebo to prevent relapses. Digestion 1987; 36: 148-61.

11 Mason JB, Moshal MG, Naidoo V, Schlemmer L. The effect of stressful life situations on the healing of duodenal ulceration. $S$ Afr Med F 1981; 60: 734-7.

12 Brunner H, Dittrich H, Kratochvil P, Brandstätter G Hentschel E, Schütze K, et al. Treatment of duodenal ulcer Hentschel E, Schütze K, et al. Treatment of duodenal

13 Okada M, Yao T, Maeda K, Yamamoto T, Saigenji K, Okada $\mathrm{Y}$, et al. Predictors of duodenal ulcer healing during treatment with cimetidine. Gut 1990 ; 31: 758-62.

14 Reynolds JC. Famotidine therapy for active duodenal ulcers A multivariate analysis of factors affecting early healing. Ann Int Med 1989; 111: 7-14.

15 Hasan $M$, Sircus $W$. The factors determining success or failure of cimetidine treatment of peptic ulcer. F Clin Gastroenterol 1981; 3: 225-9.

16 Massarrat S, Müller HG, Schmitz-Moormann P. Risk factors for healing of duodenal ulcer under antacid treatment: do ulcer patients need individual treatment? Gut 1988; 29: ulcer patie

17 Stadler Ph, Armstrong D, Margalith D, Saraga E, Stolte M Lualdi $\mathrm{P}$, et al. Diclofenac delays healing of gastroduodenal mucosal lesions. A double-blind, placebo-controlled endoscopic study in healthy volunteers. Dig Dis Sci 1991; 36 $594-600$.

18 Sonnenberg A. Dietary salt and gastric ulcer. Gut 1986; 27: $1138-42$.

19 Massarrat S, Eisenmann A. Factors affecting the healing rate of duodenal and pyloric ulcers with low-dose antacid treatment. Gut 1981; 22: 97-102.

20 Fleiss JL. Statistical methods for rates and proportions. 2nd Ed. Chichester: Wiley, 1982: 56-82.

21 Marshall BJ, Goodwin CS, Warren JR, Murray R, Blincow ED, Blackbourn SJ, et al. Prospective double-blind trial of ED, Blackbourn SJ, et al. Prospective double-blind trial of duodenal ulcer relapse after eradic
pylori. Lancet 1988 ; ii: $1437-41$.

22 Ippoliti AF, Sturdevant RAL, Isenberg JI, Binder $M$ Camacho $\mathrm{R}$, Cano $\mathrm{R}$, et al. Cimetidine versus intensive antacid therapy for duodenal ulcer. A multicentric trial Gastroenterology 1978; 74: 393-5.

23 Samloff IM, Liebman WL, Donitch NM. Serum group pepsinogen by radio-immunoassay in control subjects and patients with peptic ulcer. Gastroenterology 1975; 69: 83-90.

24 Petersen GM, Lam SK, Samloff IM, Jing J, Rotter JI. Genetic factors predict duodenal ulcer healing. Gastroenterology 1985; 88: 1348 (Abstract)

25 Van Deventer GM, Schneidman D, Walsh JH. Sucralfate and cimetidine as single agents and in combination for treatmen of active duodenal ulcers. A double-blind, placeboof active duodenal ulcers. A double-blind, placebc

26 Lam SK, Lai CL, Lee LNW, Fok KH, Ng MMT, Siu KF Factors influencing healing of duoderal ulcer. Control of nocturnal secretion by $\mathrm{H} 2$ blockade and characteristics of patients who failed to heal. Dig Dis Sci 1985; 30: 45-51

27 Clarke CA, Edwards JW, Haddock DRW, Howel Evans AW McConnell PB, Sheppard PM. ABO blood groups and secretor character in duodenal ulcer. $B M \mathcal{F}$ 1956; ii: 725-31

28 Blum AL, Armstrong D, Damman H, Fischer M, Greiner L, Haase W, et al. The effect of Helicobacter pylori on the healing and relapse of duodenal ulcer. Gastroenterology 1990 ; 98: A22 (Abstract)

29 Bauerfeind P, Cilluffo T, Fimmel CJ, Emde C, von Ritter C Köhler W, et al. Does smoking interfere with the effect of histamine $\mathrm{H}_{2}$-receptor antagonists on intragastric acidity in histamine $\mathrm{H}_{2}$-receptor antagon

30 Müller-Lissner SA. Bile reflux is increased in cigarette smokers. Gastroenterology 1986; 90: 1205-9.

31 Murthy SNS, Dinoso VP Jr, Clearfield HR, Chey WY Serial $\mathrm{pH}$ changes in the duodenal bulb during smoking Gastroenterology 1978; 75: 1-4.

32 Katschinski BD, Goebell H, Arnold R, Classen M, Fischer M Witzel L, et al. Smoking as a risk factor for slow duodena ulcer healing. Eur f Gastroenterol Hepatol 1991; 3: 443-7.

33 Battaglia G, Di Mario F, Vianello F, Aggio L, Cannizzaro R, De Lazzari F, et al. Alcohol consumption in the management of duodenal ulcer disease: a two year study. Ital $\mathcal{f}$ Gastroenterol 1985; 17: 262-4.

34 Sonnenberg A, Müller-Lissner SA, Vogel E, Schmid P Gonvers JJ, Peter $\mathrm{P}$, et al. Predictors of duodenal ulce Gonvers JJ, Peter P, et al. Predictors of duodenal
healing and relapse. Gastroenterology 1981; 81: 1061-7.

35 Gitlin N, McCullough AJ, Smith JL, Mantell G, Berman R. A multicenter, double-blind, randomized, placebo-controlled comparison of nocturnal and twice-a-day famotidine in the treatment of active duodenal ulcer disease. Gastroenterology 1987; 92: 48-53.

36 Bardhan KD. Refractory duodenal ulcer. Gut 1984; 25: 711-7.

37 Holtmann G, Armstrong D, Pöppel E, Bauerfeind A, Goebel $\mathrm{H}$, Arnold R, et al. Influence of psychological stress on the healing and relapse of duodenal ulcers. A prospective multicenter trial in 2109 patients with recurrent duodenal ulceration treated with ranitidine. Scand 7 Gastroenterol 1992; 27: 917-23.

38 Hancock L, Walsh R, Henry DA, Redman S, Sanson-Fisher R. Drug use in Australia: a community prevalence study. Med F A Aust 1992; 156: 759-64. 